\title{
Interactive comment on "Structural variations in basal decollement and internal deformation of the Lesser Himalayan Duplex trigger landscape morphology in NW Himalayan interiors" by Saptarshi Dey et al.
}

\section{Stefan Hergarten (Referee)}

stefan.hergarten@geologie.uni-freiburg.de

Received and published: 15 July 2020

In this manuscript, analyses of topography and measurements of rock strength are used to unravel the deformation pattern of the Lesser Himalayan Duplex with emphasis on rapid exhumation during the last 2-3 Myr.

While I think that this study might contribute to the solution of an important research question, I must admit that I am disappointed by the manuscript. In its present form, its quality is far off from what I expect from this team of authors. It the first author was a 
student, I would ask the supervisor to take a look at it before submitting. However, the first author is an experienced researcher who has published in highly ranked journals.

ESurfD

The problems concerning the quality of the manuscript occur at all levels. The structure is not really good at some points, e.g., parts of the discussion section read more like parts of an introduction, but the introductory part is already quite long. In general, too much of the reasoning relies son supplementary figures.

The applied morphometric methods appear to be appropriate in total, but the description does not allow for a serious assessment whether the choice of the parameters is good or not. Bumps in the order of magnitude of $100 \mathrm{~m}$ in the river profile shown in Fig. 2 do not increase my trust in the analysis. Some information is missing, e.g., the width of the swaths. Beyond this, the different metrics (channel steepness, specific stream power, channel width) are a bit isolated, and following the reasoning how they are combined to the whole picture is not easy.

Beyond these aspects, there are also technical issues that should have been detected by the coauthors. There are several errors in the text (not only typos), no all curves shown in Fig. 3 are explained, the two stretches shown in Fig. 2 b and $c$ are not consistent with the marked regions in Fig. 2 a, and even the first reference I checked randomly (Hack 1973) does nor occur in the reference list.

In sum, I have no doubt that the work behind this manuscript is good, but the manuscript itself is not ready for being published in a scientific journal in its present state. From my point of view, a thorough rewriting is necessary.

Interactive comment on Earth Surf. Dynam. Discuss., https://doi.org/10.5194/esurf-2020-37, 2020.

Interactive comment 